\title{
The ontogenetic saga of a social brain
}

\author{
Angel Roberto BarchuK, Gabriele David dos Santos, Ricardo Dias Caneschi, \\ Delcio Eustaquio de Paula Junior, Lívia Maria Rosatto Moda
}

\begin{abstract}
Departamento de Biologia Celular e do Desenvolvimento, Instituto de Ciências Biomédicas, Universidade Federal de Alfenas (UNIFAL-MG), Campus Sede, Rua Gabriel Monteiro Silva 700, Alfenas, Minas Gerais CEP 37130-000, Brazil
\end{abstract}

Received 4 April 2017 - Revised 20 July 2017 - Accepted 16 August 2017

\begin{abstract}
Queen and worker honeybees differ in a number of life-history traits, including the size of certain brain regions, such as the mushroom bodies (MBs), which are larger in workers. However, during the larval period, the differential feeding offered to queens promotes faster brain development. As a result, members of this caste have larger brains than workers. This developmental process is accompanied by the higher expression of several neurogenic genes. Nonetheless, a caste-specific shift in relative brain growth occurs during the next developmental stage. The suggested molecular underpinnings of this phenomenon are variations in hormonal environments, which may mediate higher cell death rates in the queen's brain than in the workers'. The brain development of this highly eusocial bee is thus a paradoxical case that may represent an evolutionary by-product of the reproductive division of labour in species with female size diphenism.
\end{abstract}

\section{Apis mellifera / honey bee / development / caste / phenotypic plasticity}

\section{INTRODUCTION}

Adult honeybee queens are easily distinguished from workers based on their external morphology. The queens are rotund creatures that move slowly, whereas workers are comparatively smaller and exhibit constant, agile movements. This first impression might suggest that queens have large organs, of which the ovaries are fair representatives. In fact, queens do develop a large body with a large reproductive system, which is the anatomical representation of their primary task within a colony, i.e. reproduction. Workers, on the other hand, develop a specific morphological character set that allows them to perform the innumerable tasks associated with maintaining the colony, such as foraging, nursing the brood, nest cleaning, nestmate recognition, and guarding.

Corresponding author: A. Barchuk, barchuk@unifalmg.edu.br

Manuscript editor: Klaus Hartfelder
The morphogenetic fields governing castespecific systems and organ development have been the focus of research in recent decades. In developmental biology, morphogenetic fields are discrete regions of developing organisms that function as the major units of development (Levin 2012; Gilbert and Barresi 2016). Since the general fate of their cells is genetically determined, changes in these fields bring about evolutionary changes. One morphogenetic field that has attracted attention since the early work of Erber (1975) is that of the honeybee brain. Studies on the ontogenetic development of the brain diphenism found in adult honeybees have revealed an interesting phenomenon. The differential nutritional inputs received by developing larvae boost the development of the "bipotential" brain found in embryos and the initial phases of larval development (primarily L1-2) into that of presumptive queens thus resulting in a bigger brain compared to that of presumptive workers (Moda et al. 2013). This picture, nevertheless, shifts during subsequent developmental stages 
before adult emergence. Specifically, morphogenetic reorganisations occur so that the brain, which is larger in queen larvae, is relatively smaller than that of workers in the pharate-adult stage (Figure 1). Lastly, development assures that the brains of newly emerged bees of both castes are alike in size and, as the queen is larger, adult workers feature a proportionally larger brain than adult queens. This developmental phenomenon does not have a straightforward biological explanation, and we will discuss some of its morphological and molecular underpinnings in the following sections.

\section{HONEYBEE DIPHENISM AND CASTE DIFFERENTIATION}

The genus Apis differs from the extremely rich group of bees based on their evolutionary trait of highly eusocial organisation, a feature shared with the stingless bees (Meliponini). These highly eusocial bees show caste morphology in addition to

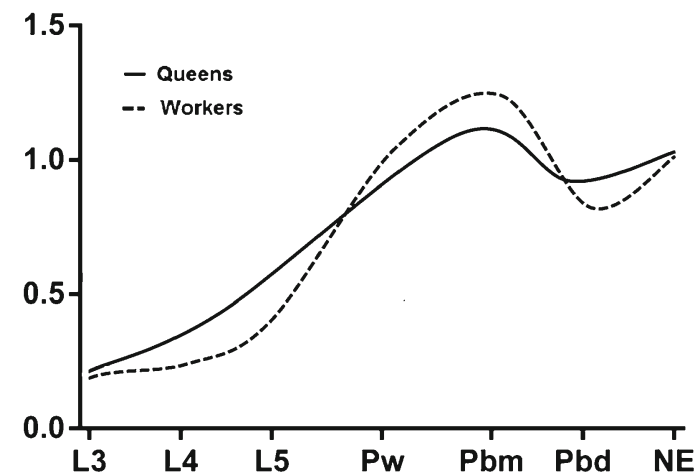

Figure 1. The brain size shift between developing Apis mellifera queens and workers. The queen's brain during the larval stage develops more rapidly than the worker's. This pattern shifts during the next stage (pu$\mathrm{pal} / \mathrm{pharate}$-adult), with the end result being that newly emerged queens and workers feature equal-sized brains, although the brain/body ratio favours workers. L3: third larval instar; L4: fourth larval instar; L5: fifth larval instar; Pw: white-eyed pupa, unpigmented cuticle; Pbm: brown-eyed pupa, intermediary pigmented cuticle; Pbd: brown-eyed pupa, dark pigmented cuticle; NE: newly emerged adult. Values on the y-axis are arbitrary units only to demonstrate the relative developmental trend (modified from Moda et al. 2013; see also Section 6. Honeybee brain development during the pupal and pharate-adult stages). cooperative brood care, reproductive division of labour and overlap of generations (Wilson 1971). These complex traits have molecular underpinnings that may have evolved from solitary-living bee species. In this context and as an evolutionary-developmental hypothesis, the existence of evolutionarily conserved molecular pathways ("genetic toolkits") has been suggested. Such pathways would play a role in controlling the feeding behaviour and reproduction of both solitary and highly eusocial insects and thus would underlie the evolution of such complex traits (Toth and Robinson 2007). Genomic evidence, however, supports that the only molecular characteristic that plays a role in the evolution of sociality is the increasing complexity of gene expression networks, rather than the existence of a gene-set for sociality. The transition from solitary to social living seems to have required an increase in gene regulatory system capabilities, including a higher number of genes regulated by DNA methylation and gains in transcription factor-binding sites. Many of such changes constitute targets of regulatory factors that act to control brain gene expression and neurogenesis (Kapheim et al. 2015). Interestingly, the nervous system size is a morphological trait that develops differentially between honeybee castes. Honeybee workers have double the relative antennal surface area compared to queens, have more chemoreceptive plates per antenna, and exhibit a higher number of facets of their compound eyes (Michener 1974). Accordingly, workers have larger antennal lobes and mushroom bodies (MBs), altogether constituting a sensory armamentarium for workers to cope with the broad range of duties they need to perform in a colony (Menzel 2014). Workers also have special, "tool-like" organs that allow them to perform these duties, such as a pollen press and a corbicula, a long proboscis, large hypopharyngeal and mandibular glands, wax glands, Nasanov's gland, and a straight and barbed sting. On the other hand, queens feature the complete morphophysiological set of a reproductive machine, with large ovaries and spermatheca and developed secretory glands for scents that control workers' behaviour (Snodgrass 1910; Michener 1974; Pankiw et al. 1998, Hoover et al. 2003; see also in Miklos and Maleszka 2011). 
The first working model of the developmental processes that lead to caste differentiation in honeybees was published after an effort to synthesise DNA microarray hybridization results and data from the literature (Barchuk et al. 2007). The model states that the quality and amount of food that the bipotential female larvae receive determine the developmental trajectories they follow, ultimately giving rise to morphologically distinct queens and workers. Specifically, differential feeding would differentially activate the nutrientsensing pathway Tor (Target of Rapamycin), which would then differentially induce the synthesis of juvenile hormone $(\mathrm{JH})$ in the corpora allata. This signalling pathway and that of Insulin/ILPs, as well as the differential availability of nutrients in the haemolymph (systemic level response), would lead to the differential development of specific organs and systems (morphogenetic fields level response, i.e. brain, ovaries, legs, etc.). This developmental process would require the participation of molecular effectors (e.g. gene expression cascades), some of which would be regulated epigenetically by differential gene methylation. High signalling levels would allow the prospective queens' body to grow and guarantee the development of large ovaries, as well as repress the development of worker specific organs (leg structures, etc.) (Barchuk et al. 2007). This model has proven to be useful, and virtually, all interactions have been supported experimentally (Patel et al. 2007; Kucharski et al. 2008; Maestro et al. 2009; Mutti et al. 2011). All, that is, except for the confounding data on nervous system development that have been obtained from microarray experiments using whole body samples.

The observed split in the developmental trajectories was suggested to occur early in larval life (Cameron et al. 2013), very likely due to significant differences in the nutrient constituents of worker and royal jellies (Leimar et al. 2012). Pioneering work had already suggested the influence of early acting food components in caste differentiation in the honeybee (Asencot and Lensky 1976), and this view recently received support by the identification of small key molecules in honeybee larval food, namely, microRNAs (Guo et al. 2013; see also Ashby et al. 2016). Small hydrophilic molecules (e.g.
microRNAs in royal jelly), which are also present in the heads of nurse bees, were suggested to drive queen development (queen determinator) many years ago (Rembold and Hanser 1964; Weaver 1966; see also Rembold et al. 1974). Another suggested promoter of caste differentiation is a member of the major royal jelly proteins, royalactin, although the activities of this protein have not been comprehensively integrated into the model outlined above (Kamakura 2011). Royalactin has been suggested to promote queen development via the activity of the epidermal growth factor receptor. There is, however, a vigorous debate regarding the role of this signalling pathway in honeybee caste development (Kucharski et al. 2015; see also Buttstedt et al. 2016 and Kamakura 2016).

Studies focusing on the morphogenetic fields of honeybee castes have primarily considered the reproductive system, especially the development of the ovaries, which are very large in queens (approximately 200 ovarioles) compared to those of workers (approximately 12 ovarioles) (Snodgrass 1910; Michener 1974). This ovarian diphenism develops during the larval stage, in which queen ovaries respond to the larval overloading of royal jelly by undertaking marked ovariole development under the molecular protection of juvenile hormone. This hormone was shown to prevent cell death in queen ovaries. Worker ovaries, on the other hand, in response to a different nutritional input and low levels of $\mathrm{JH}$, undergo extensive cell death, leading to differential ovary development between honeybee castes (Capella and Hartfelder 1998; Schmidt Capella and Hartfelder 2002; Antonialli and CruzLandim 2006; Lago et al. 2016). The molecular underpinnings of another morphogenetic field, that of the hind leg structures, have recently been revealed. Bomtorin et al. (2012) showed that the development of the "shaved tibia" used by workers to carry pollen (pollen basket) depends upon ultrabithorax expression during prepupal and early pupal phases. This finding was then confirmed by Medved et al. (2014) using gene expression interference by RNAi.

The honeybee brain, a third morphogenetic field, has also attracted a good deal of scientific attention. In the animal kingdom, eusociality is 
phylogenetically considered an unusual trait, since it is nearly confined to insects (ants, wasps, termites, and bees; Wilson 1971), in addition to occur in some crustaceans (Emmet et al. 2000) and mammals [mole-rats (Burda et al. 2000) and humans (Foster and Ratnieks 2005)]. Eusocial insects are capable of executing complex, cooperative, and altruistic tasks in a colony environment. The capacity of honeybees to learn how to reach food sources and communicate that knowledge to conspecifics makes them powerful models to understand the basis of cognition (Chittka and Niven 2009; Menzel 2012). Moreover, their small, plastic, and versatile brain allows researchers to trace the routes of memory formation at cellular and molecular levels (Menzel 2014; Cristino et al. 2014; Haberkern and Jayaraman 2016). Thus, it is worth noting here some of the general aspects of honeybee brain biology. We will subsequently present and discuss the morphological and molecular aspects that underlie the ontogenetic saga of the honeybee brain.

\section{THE ADULT HONEYBEE BRAIN}

The honeybee nervous system consists of a large cephalic ganglion, the brain, which is connected to a series of segmental ganglia along the ventral nerve chord (Snodgrass 1935). The honeybee brain is a small organ consisting of 1 million neurons with their neuropils, structures that are composed of axons, dendrites and glial cell processes that form a dense region of synapses. The neuropils comprise three regions of the brain: the protocerebrum, deutocerebrum, and tritocerebrum. The deutocerebrum essentially contains the antennal lobes, where 60,000 odorant receptor cells are concentrated. The tritocerebrum consists of two bilateral small lobes that innervate the labrum and the digestive tract. Lastly, the protocerebrum is characterised by two optic lobes, which are responsible for the conduction of visual image information to higher centres; the central body, a neuropil that controls locomotor behaviour; and a pair of MBs, which are critical elements responsible for learning (Snodgrass 1935; Strauss and Heisenberg 1993; Menzel 2012). The MBs are higher-order processing centres that integrate stimuli from the optic lobes and antennal lobes. The mushroom bodies are composed of two calyces, each with three concentric regions: the lip, where olfactory information is received; the collar, which receives visual information; and the layered basal ring, where visual and olfactory inputs converge. Because of their architecture, the calyces are also known as "cup-like" neuropils, which contain hundreds of Kenyon cells (KCs). The KCs are divided into three subpopulations according to the input sensory stimulus: visual, olfactory and mechanosensory. The KCs dendritic arborizations spread to the calyces, and their axonal projections form the peduncles, which are divided into alpha (vertical) and beta (median) branches, also termed the alpha and beta lobes (Mobbs 1982; Kenyon 1896; Farris et al. 1999; Strausfeld 2002).

Because of their physiological plasticity, the honeybee MBs have been extensively studied throughout the entire development of adult behaviour in workers. There is a decrease in $\mathrm{KC}$ volume and an increase in MB volume associated with foraging (Withers et al. 1993). No neurogenesis has been observed in adult brains, and studies using Golgi impregnation showed that intrinsic MB dendrites of older workers were typically more spread out and longer than those of young bees. These characteristics apparently reflect the effects of learning and memory in terms of dendritic growth of intrinsic neurons and neuropil volume (Farris et al. 2001; Fahrbach et al. 1995a; Withers et al. 1993). In comparison, the architecture of a queen's brain changes during adulthood (from 1 day to 5 months old). Specifically, the population of KCs decreases by approximately $30 \%$, and the MB volume increases between 25 and $50 \%$. In this context, an important feature shared by both castes is exposure to high levels of JH prior to neuropil development, suggesting that anatomical changes in KCs and MBs are under endocrine control (Robinson 1992; Fahrbach et al. 1995b).

\section{EMBRYOLOGICAL ORIGIN OF THE HONEYBEE BRAIN}

In 1915, J.A. Nelson published a monograph of 282 pages and 95 figures that represented and described various aspects of honeybee development. Depending on temperature, development 
from oviposition to larval eclosion takes $70-76 \mathrm{~h}$, and this period is divided into 15 stages based on morphological characteristics (Nelson 1915). Some years later, Du Praw refined Nelson's work using innovative techniques and established 10 stages of honeybee embryogenesis (Du Praw 1967). Later, using scanning electron microscopy, Fleig and Sanger (1986) observed that honeybee nervous system development begins $44 \mathrm{~h}$ after fertilisation, at Du Praw's stage 9. Two longitudinal thickenings or ridges extending along the ventral side of the embryonic germ band go on to form the ventral nerve cord. Cephalically, a proliferative area in the head ectoderm gives rise to three prominences, the protocerebrum, deutocerebrum and tritocerebrum (Nelson 1915; Du Praw 1967; Fleig and Sanger 1986). These swellings compose the brain neuropils, the architecture of which is composed of neurons, their processes, and glial cells.

Using grasshopper embryos as a model, Wheeler (1891) studied the histogenesis of neurogenic tissues and identified the progenitors of neurons and glia, which are termed neuroblasts (NBs). Wheeler observed that after gastrulation, the ventral ectoderm (or neuroectoderm), consists of two kinds of cells, NBs and dermatoblasts, which will form the integumentary system. The NBs start to bud off smaller cells, the ganglion cells, by mitotic division. Other researchers have reported the same observations in Orthoptera, Dermaptera, the mason bee and beetles (Wheeler 1891; Nelson 1915). Since this time, experiments performed with Drosophila melanogaster have elucidated many of the molecular and cellular mechanisms related to nervous system development, with a focus on NB specification, differentiation and segregation (Knust and CamposOrtega 1989; Campos-Ortega and Hartenstein 1997; Doe 1992; Urbach and Technau 2003). Signalling mechanisms that are governed by specific families of genes that include pre-patterning, proneural, and neurogenic genes, orchestrate the delamination of NBs from the neuroectoderm (Knust and Campos-Ortega 1989; CamposOrtega and Hartenstein 1997; Hartenstein and Wodarz 2013). There are two types of NBs, type I and type II. Type I NBs divide asymmetrically and give rise to both another NB - in a process termed self-renewal-as well as a smaller cell referred to as a ganglion mother cell (GMC). The GMC is committed to differentiate into a neuron and glial cell. Type II NBs can also selfrenew or can form intermediate neural progenitors (INPs), which give rise to GMCs (Boone and Doe 2008; Homem et al. 2015; Altenhein 2015; Koniszewski et al. 2016).

Some aspects of nervous system development are conserved in hemi- and holometabolous insects. The spatial arrangement, timing of delamination, and molecular network that specifies the NBs are strongly conserved between species (Urbach and Technau 2003; Koniszewski et al. 2016). On the other hand, NBs that form specific neuropil structures, such as the MBs, differ between species in number, arrangement, and proliferation behaviour. In A. mellifera, a compact group of 40-45 NBs per hemisphere forms the MBs, whereas 2-6 NBs are found in Diptera, Hemiptera, and Neuropteroidea (Malun 1998; Farris et al. 1999; Ito and Hotta 1992; Cayre et al. 1996). In the following section, we discuss their participation in the development of the larval honeybee brain.

\section{HONEYBEE BRAIN DEVELOPMENT DURING THE LARVAL STAGE}

The brain of a recently hatched honeybee larva is similar to that of other insects and does not seem to exhibit morphological differences between the castes much before the fourth larval instar, L4 (Nelson 1924; Moda et al. 2013). This lack of observed differences, however, might be due to methodological limitations and the challenge involved in dissecting such small organs. During the early larval development, the honeybee brain almost completely fills the head capsule and consists of two symmetrical proliferating halves with a central mass of nerve fibres, all surrounded by a neurilemma (Nelson 1915, 1924; Farris et al. 1999). The most prominent part of each hemisphere is the ontogenetic derivative of the protocerebrum, with its conspicuous optic lobe. The halves of the protocerebrum are joined by nerve fibres, forming the supraoesophageal commissure. The deutocerebrum and tritocerebrum derivatives seen during this period are very small 
and become organised below the protocerebrum, representing the precursors of the antennal lobes and, together with the suboesophageal commissure, form a ring that surrounds the oesophagus (Nelson 1924).

Comprehensive studies on postembryonic brain development in A. mellifera were published by Malun (1998) and Farris et al. (1999). These authors used basic histological analyses combined with BrdU incorporation and immunolocalization of a MB neuropil marker (cAMP-dependent protein kinase type II) and myocyte enhancer factor 2, a marker of noncompact KCs. Using these techniques, the morphological developmental dynamics of worker MBs was described from the first instar larva to adult eclosion. These studies showed that the brain in L1 and L2 (see Table I) features two clear NB clusters (proliferation centres for KCs) per hemisphere, a small medial cluster with approximately 16 cells and a large lateral cluster with approximately 45 cells (Malun 1998; Farris et al. 1999; see also Urbach and Technau 2003). Both clusters are delimited from the rest of the brain mass by a thin layer of early GMCs (see also Hähnlein and Bicker 1997). There are no calyces, lobes, or pedunculi observed at these developmental phases. From the third larval instar to metamorphosis, the NB clusters undergo a steady increase in both volume and the number of cells, including some scattered GMCs. These two types of proliferating cells are responsible for giving rise to the organisation of the brain. A NB divides asymmetrically to give rise to another NB and a smaller GMC, the latter of which divides symmetrically into two KCs (Farris et al. 1999). Thus, at the third larval instar, it is possible to identify the first manifestation of peduncular neuropile ramifications, indicating the differentiation of the first KCs (future outer compact cells, originated by mitoses of GMCs migrating from the NB cluster). This is clearly seen from the fourth larval stage onward, when these cells come to surround the NB clusters and form a thin sheath of small cells that extend axons and form the primordia of the branching pedunculi (Farris et al. 1999). All of these structures continue to increase in size and thickness, and by the spinning phase of the fifth instar (L5S), a distinct layer of GMCs becomes apparent between the NB cluster
Table I. Developmental phases of A. mellifera considered in this work (for details see Rembold et al. 1980 and Michellete and Soares 1993)

\begin{tabular}{|c|c|}
\hline Abbreviation & Developmental phase \\
\hline $\mathrm{E}$ & Embryo \\
\hline $\mathrm{L} 1$ & First instar larva \\
\hline $\mathrm{L} 2$ & Second instar larva \\
\hline L3 & Third instar larva \\
\hline L4 & Fourth instar larva \\
\hline L5F1 & Fifth instar larva, feeding phase 1 \\
\hline L5F2 & Fifth instar larva, feeding phase 2 \\
\hline L5F3 & Fifth instar larva, feeding phase 3 \\
\hline L5S1 & Fifth instar larva, cocoon-spinning phase 1 \\
\hline L5S2 & Fifth instar larva, cocoon-spinning phase 2 \\
\hline L5S3 & Fifth instar larva, cocoon-spinning phase 3 \\
\hline PP1 & Fifth instar larva, prepupa 1 \\
\hline PP2 & Fifth instar larva, prepupa 2 \\
\hline PP3 & Fifth instar larva, prepupa 3 \\
\hline $\mathrm{Pw}$ & White-eyed pupa, unpigmented cuticle \\
\hline $\mathrm{Pp}$ & $\begin{array}{l}\text { Pink-eyed/pharate-adult transition, } \\
\text { unpigmented cuticle }\end{array}$ \\
\hline Pdp & $\begin{array}{l}\text { Dark pink-eyed pharate-adult, } \\
\text { unpigmented cuticle }\end{array}$ \\
\hline $\mathrm{Pb}$ & $\begin{array}{l}\text { Brown-eyed pharate-adult, unpigmented } \\
\text { cuticle }\end{array}$ \\
\hline $\mathrm{Pbl}$ & $\begin{array}{l}\text { Brown-eyed pharate-adult, light } \\
\text { pigmented cuticle }\end{array}$ \\
\hline $\mathrm{Pbm}$ & $\begin{array}{l}\text { Brown-eyed pharate-adult, intermediary } \\
\text { pigmented cuticle }\end{array}$ \\
\hline Pbd & $\begin{array}{l}\text { Brown-eyed pharate-adult, dark } \\
\text { pigmented cuticle }\end{array}$ \\
\hline $\mathrm{NE}$ & Newly emerged adult \\
\hline
\end{tabular}

and the surrounding sheath of KCs. In addition, the pedunculi that originate from the base of each cluster during the preceding fifth instar feeding phase (L5F) become more evident (Farris et al. 1999). The morphogenetic field of the MBs is thus formed by concentric layers of proliferative cells. Knowledge of the development of the MBs and other honeybee brain regions such as the optic lobes (Marco Antônio and Hartfelder 2016) has broad scientific interest given that, for example, pesticides used in agriculture to control insects target the brains of larval bees (Tomé et al. 2012; Tavares et al. 2015). 
Using phalloidin and DAPI staining of wholemount brains, Moda et al. (2013) showed clear peduncular organisation in worker larvae in the L5F phase. In contrast, this organisation was already observed to the end of L3 in queen larvae (Figure 2a). Moreover, these authors reported that MB calyces first appear at the beginning of the L5S phase in workers and slightly earlier in queens (L5F). This neuropil differential morphogenesis is also accompanied by a marked difference in MB cell proliferation. Cell proliferation rates, as assessed by EdU staining, increasingly differ between castes from L4 until L5S, difference that favours queen larvae (Moda et al. 2013). Higher levels of brain neuron proliferation in queen larvae were previously demonstrated by

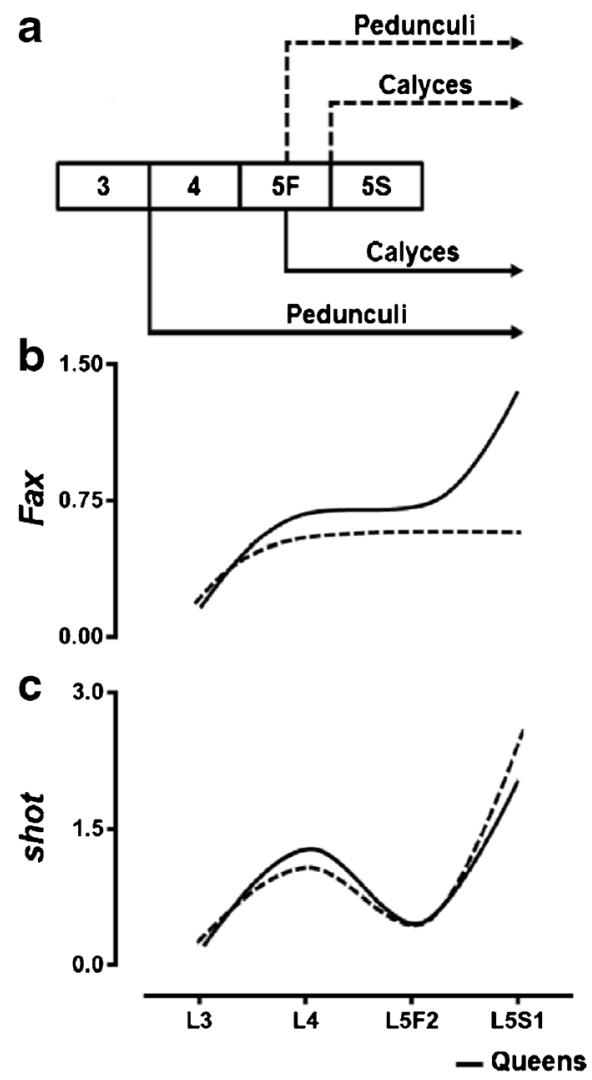

Roat and Cruz Landim (2008). These authors, by measuring conventional histological sections, showed that the brain of queen L5 larvae features an approximately $45 \%$ larger NB area than the brain of worker larvae, and this difference was seen to persist until the middle of the pharateadult developmental period. During the prepupal stage in workers, the number of NBs per cluster of the brain peaks at approximately 500; a significant number of KCs are generated and located externally to the cluster (non-compact cells), and the calycal neuropil appears along with the almost completely grown $\alpha$ and $\beta$ lobes (Malun 1998; Farris et al. 1999). Information on general aspects of honeybee larval development and metamorphosis can be obtained from Cruz-Landim (2009).
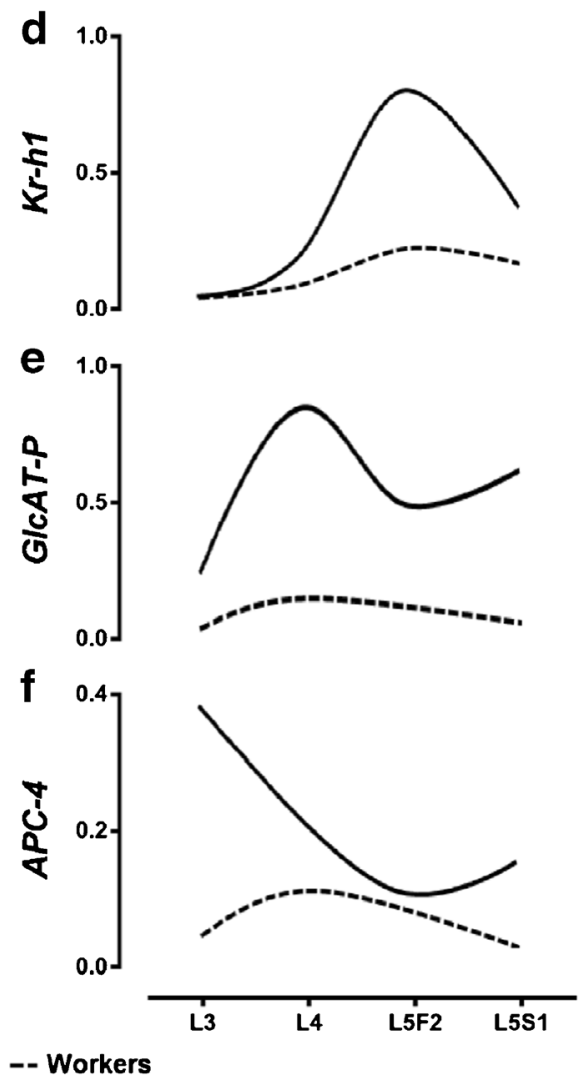

Figure 2. The developmental dynamics of the larval brain favour the queen honeybee caste. a Summary of the timing of morphological differentiation in queen and worker larval MB structures. Continuous lines, queens. Discontinuous lines, workers. b-f General transcription profiles of key genes in the larval differential brain development between honeybee castes. b failed axon connection, c short stop, d krüppel homologue -1, e galactosylgalactosylxylosylprotein 3-beta-glucuronosyltransferase $P, \mathbf{f}$ anaphase promoting complex 4 . Modified from Moda et al. (2013). 
The morphological dynamics of differential brain development observed between queen and worker larvae may be conceived as a natural experiment and, accordingly, the fate of the respective morphogenetic fields should be molecularly established by the differential expression of specific genes. The first genes suggested to play a role in differential neurogenesis between honeybee castes were reported by Barchuk et al. (2007). Nonetheless, as these genes were identified using genome-wide analyses of whole-body RNA samples, they may not reflect the actual biology of a small organ like the brain, whose contribution of differentially expressed genes is likely to be minimal. With this limitation in mind, Moda et al. (2013) carried out genome-wide analyses on RNA samples taken from L4 brains of queens and workers, identifying 16 differentially expressed genes. RT-qPCR assays were used to pinpoint five genes whose expression may be responsible for the differential brain development between castes during the larval phases, with all five being more highly expressed in queens (Figure 2b-f): failed axon connection (fax), krüppel homologue-1 (kr-h1), galactosylgalactosylxylosylprotein 3-betaglucuronosyltransferase $P$ (GlcAT-P), anaphase-promoting complex 4 (APC-4), and short stop (shot). The differential expression of these genes was confirmed by immunolocalization (Moda et al. 2013). Fax, GlcAT-P, and shot proteins are known to participate in fasciculation processes, usually leading to the development of neuropils in the brain and in the peripheral nervous system (Liebl et al. 2000; Pandey et al. 2011; Reuter et al. 2003; see also Farris and Sinakevitch 2003 for data on dachshund gene regulatory function in brain development). $k r-h 1$, on the other hand, is a $\mathrm{JH}$ immediate response gene that also acts to integrate the ecdysteroid pathway and is known to have functions associated with neurogenesis (Shi et al. 2007; Jindra et al. 2013). APC, combined with the coactivators $\mathrm{Cdh} 1$ and $\mathrm{Cdc} 20$, has functions beyond its classical mitotic role. For example, APC regulates neurogenesis, glial differentiation and migration, neuronal morphogenesis, survival and metabolism, synapse formation and plasticity, as well as learning and memory (Huang and Bonni 2016). Other neurogenic genes have also been studied in the context of compound eye development in honeybee workers and drones (Marco Antônio and Hartfelder 2016).

Taken together, the available morphological and molecular evidence indicates that the differential neurogenesis favouring the brain development of the honeybee queens is due to early differences in nutritional signalling between queen and worker larvae. These differences promote the establishment of caste-specific hormonal environments, which in turn drive the expression of different groups of effector genes (Ulrich and Rembold 1983; Hartfelder and Engels 1998; Barchuk et al. 2007; Maestro et al. 2009; Mutti et al. 2011; Moda et al. 2013). These may be considered to be the molecular responsible for the development of the initially larger brain seen in queen larvae. Hence, this diphenism can be interpreted as representing a heterochronic effect of differential larval feeding regimes, which after morphological reorganisations leads to the development of distinct nervous systems proper of adult honeybee female castes.

\section{HONEYBEE BRAIN DEVELOPMENT DURING THE PUPALAND PHARATE-ADULT STAGES}

Brain structures and the distinct lip and collar regions of the MBs continue developing and increasing in size during the pharate-adult period of development, ultimately reaching final adult organisation and size. On the other hand, the number of NBs and the volume of the NB clusters start decreasing from the prepupal/pupal stages, both in queens and workers (Malun 1998; Farris et al. 1999; Roat and Cruz Landim 2008, 2010a, b). $\mathrm{KCs}$ continue proliferating, and by the beginning of pharate-adult development ( $\mathrm{Pb}-\mathrm{Pbl})$, a third type of cells appears and forms the inner compact cell layer. At this time, the morphogenetic field of the MB is formed by clusters of a few NBs "capped' by active GMCs, all surrounded by layers of various types of KCs. During the next developmental phases of the pharate-adult period, the morphogenetic field starts to be interiorly remodelled by cell death events suffered by the remaining proliferative cells (Malun 1998; Farris et al. 1999; Roat and Cruz Landim 2008, 2010a, 
b). The cell death events within NB clusters start immediately following an abrupt cessation of cell proliferation (Ganeshina et al. 2000). Using BrdU incorporation and TUNEL assays, these authors showed that both events are sequentially coupled and coincide temporally with a minor peak in ecdysteroid titres during the middle of the pharate-adult period of development (Pinto et al. 2002). The functional association between ecdysteroids and the triggering of cell death in the honeybee brain was further demonstrated by the manipulation of hormone levels. Using 20hydroxyecdysone injections in live pharate-adult bees and squash preparations of the brains, Malun et al. (2003) demonstrated that this hormone acts by reducing mitotic activity in NB clusters. A similar action of ecdysteroids on nervous system reorganisation was demonstrated in the stingless bee Melipona quadrifasciata anthidioides, where these steroid hormones regulate cell death and ventral nerve cord shortening (Pinto et al. 2003).

Interestingly, the observed differential neurogenesis and rate of cell death in pharateadult brains following the cessation of cell proliferation are caste specific. The MBs of queens exhibit far more cell death than those of workers (Roat and Cruz Landim 2008, 2010a), and differential cell fates are also observed in other brain regions, such as the optic (Roat and Cruz Landim 2010b) and antennal lobes (Roat and Cruz Landim 2011). In all cases, these events favour the development of larger structures in the worker brain. This outcome has also been shown using immunostaining techniques with confocal fluorescence microscopy. Groh and Rössler (2008) reported that the glomerular volume (and the microglomeruli number in the MB-calyx lip) in newly emerged workers is slightly larger than in queens, even though the development of the olfactory synaptic neuropil of the antennal lobe and the $\mathrm{MB}$ is approximately 4 days faster in queens. Interestingly, the number of microglomeruli in the MB-calyx is under brood temperature control, such that any variation from the normal intracolony temperature promotes the development of smaller structures (Groh et al. 2004), thereby pushing the resulting brain phenotype to that of queens. This finding led the authors to propose that the observed accelerated development of the queen olfactory pathway results in diminished olfactory wiring in members of this caste, which might have physiological implications regarding olfactory learning skills in adult bees.

The observed beginning of caste-specific brain development early in the pharate-adult stage might be under combinatorial hormonal control. Ecdysteroid titres are higher in queens than in workers during the entire larval stage and the pupal phase (Pw, see Rachinsky et al. 1990; Pinto et al. 2002) and seem to differ only slightly in their profile during the subsequent pharateadult stage. $\mathrm{JH}$ titres are also higher in queens during the whole larval stage, reaching basal levels at the larval-pupal moult and remaining at this level until the end of pharate-adult development (Hartfelder and Engels 1998). It is possible that neurogenesis is favoured in queen larvae by a combination of high nutritional input in the presence of high levels of developmental hormones (ecdysteroids and $\mathrm{JH}$ ), the production of which is thought to depend on nutrition. However, during the next developmental stage (larval-pupal moult and pupal-pharate-adult phases), the high ecdysteroid titres that characterise queens, but now in the absence of JH, push the cell death/ proliferation ratio towards queens and now benefit worker brain development. The cell deathinducing effects of ecdysteroids and the protective effects of $\mathrm{JH}$ have been demonstrated to play a role in other insect model systems, including optic lobe development in D. melanogaster (Riddiford et al. 2010; see Monsma and Booker 1996; Ress et al. 2000; Wu et al. 2006; Parthasarathy and Palli 2007, for examples in other model systems).

By applying comparative morphometric analyses of histological sections, we found that brain development favouring workers begins as early as the white-eyed, unpigmented cuticle pupa phase $(\mathrm{Pw})$, immediately following the larval-pupal moult (Figure 3a-b). This caste-specific morphometry continues through pharate-adult development, with brains showing a progressively larger total area in both castes. However, the differential morphometry that favours pharate-adult workers vanishes at the end of this developmental period (Pbd-NE), when the brains of queens appear to be slightly larger than those of workers (see Table I for developmental staging). 

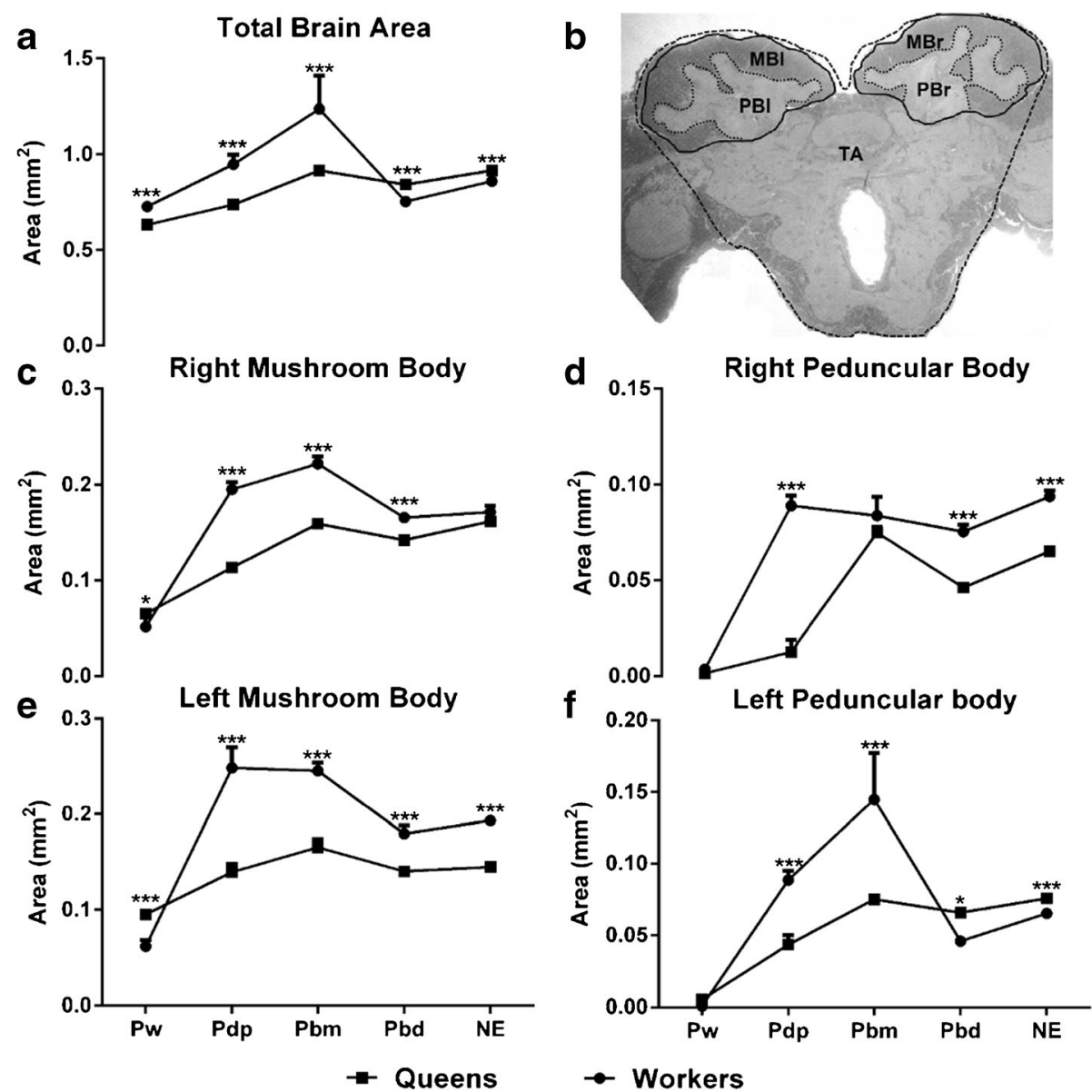

Figure 3. The development of the pupal and pharate-adult brain favours the worker caste. In $\mathbf{a}$ and $\mathbf{b}$, the total brain area excludes that of the optic lobes (delimited by the outermost discontinuous line shown in $\mathbf{b}$. Brains $(n=5$ per phase per caste) were dissected in $4 \%$ paraformaldehyde, dehydrated and embedded in Leica Historesin. The brains were carefully sectioned $(3 \mu \mathrm{m})$ in series, the largest slices $(6-7$, corresponding to the medium part of the brain) glued to a slide and the slice with the largest width of the brain was always used for measurements. The sections were stained with basic fuchsin and methylene blue, and the images were captured using a Zeiss Axio Lab microscope equipped with Zeiss Axio Vision software. The areas were measured using ImageJ software (https://imagej.nih. gov/ij/). All measurements (different brain regions) were performed with the same bee samples. Pw, white-eyed, unpigmented cuticle pupa; Pdp, dark pink-eyed pharate-adult, unpigmented cuticle; Pbm, brown-eyed pharate-adult, intermediary pigmented cuticle; $\mathrm{MBl}$ and $\mathrm{MBr}$, left and right $\mathrm{MBs}$, respectively; $\mathrm{PBl}$ and $\mathrm{PBr}$, left and right peduncular bodies, respectively; $\mathrm{TA}=$ total brain area. Means $\pm \mathrm{SE}$; two-way ANOVA followed by Bonferroni test, $* p>0.05 ; * * * p>0.001$.

MBs as a whole are pretty similar in size in both castes at the Pw phase (actually, calices are still a bit larger in queens, Figure 3e) and favour workers during the following developmental phases. This rule holds with the exception of the left peduncular bodies, which experience a shift at $\mathrm{Pbm}-\mathrm{Pbd}$, favouring queen brains (see Peduncular
Body in Figure 3d, f). Furthermore, right-side calices are quite similar in size in NE bees (Figure 3c). As there is no very clear size difference in MBs regions between queens and workers in $\mathrm{Pw}$, the observed difference in total brain area favouring the worker in $\mathrm{Pw}$ is likely due to differences in the antennal lobe and suboesophageal 

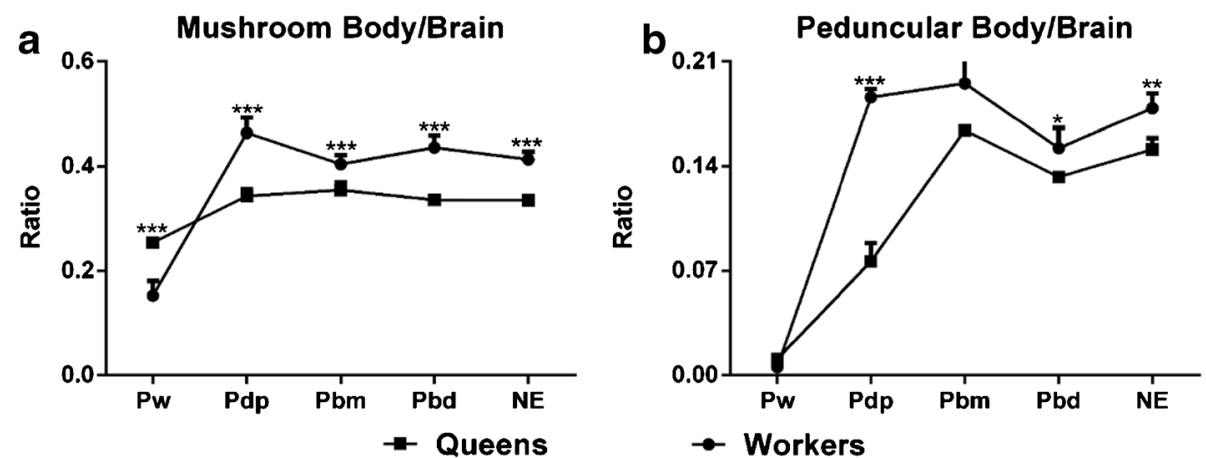

Figure 4. Mushroom body and peduncular body/brain ratios of $\mathrm{Pw}$ and pharate-adult queen and worker honeybees. a $\mathrm{MB} /$ brain ratios. b Peduncular body/brain ratios. For details on the histological analysis and description of the developmental stages, see Figure 3. Means \pm SE; two-way ANOVA followed by Bonferroni test, $* p>0.05$; $* * p>0.01 ; * * p>0.001$.

ganglionic areas (Figure 3). A similar, though opposite explanation, can be applied to the variation in total brain area favouring queens in PbdNE. This hypothesis is in agreement with the classic view, which describes adult worker MBs as being larger than those of queens (see Michener 1974; Miklos and Maleszka 2011).

Morphometric data thus support the abovementioned findings regarding hormone action on cell proliferation/death in pharate-adult brains. The clear pattern of brain size diminution after the Pbm phase in both castes coincides with the previous ecdysteroid peaks that are typical of this developmental stage (Pinto et al. 2002). It is possible that a molecular cascade promoted by differential variation in ecdysteroid levels leads to differential brain cell death and survival between the castes, causing worker brains to become transiently larger than those of queens. Taken together, the morphometric data support the classic notion of adult worker brains being proportionally larger than those of queens (brain size/body size) and show that MBs per se are larger in workers than in queens (Figures 3 and 4), with all of these differences appearing from the beginning of the pharate-adult developmental stage (Pdp). As MBs are the integrative centre of the brain, the observed difference in size that favours workers clearly fits with the demands of the broad behavioural repertoire of this caste. A similar morphobehavioural correlation was found in other social insects, such as ants. In these insects, workers with the broadest task repertoire and behavioural plasticity have the largest MBs, and those with the highest degree of task specialisation have the smallest MBs (Feinerman and Traniello 2016). This trade-off has evolutionary significance and aligns well with the brain diphenism seen in honeybees.

The observed morphological differentiation in the developing brain of queens and workers during the pharate-adult stage is currently under molecular investigation. Using a transcriptomic approach, Vleurinck et al. (2016) detected 1760 differentially expressed genes (DEGs) in the brain tissue of queens and workers at Pdp phase. Of these genes, 902 were upregulated in workers and 858 were upregulated in queens. These DEGs were found to be associated with several molecular processes, such as cell surface receptor signalling, RNA metabolism, DNA-templated transcription, phosphorus metabolic processes, and nucleotide binding. Interestingly, almost all of the DEGs (1623) were protein-coding genes, with only 43 being found to transcribe non-coding RNAs. Of the total number of DEGs, approximately $40 \%$ appear to be differentially spliced, with most of these being proteincoding genes (Vleurinck et al. 2016). Recently, our group also used a genome-wide approach (microarray hybridization) to identify more than 300 DEGs in the brain of queens and workers at the beginning of the pharate-adult stage (Pp), many of them related to neurogenic processes and cell death prevention (unpublished). Additional studies are necessary to pinpoint the extent to which each these genes participates in the differential neurogenesis between pharate-adult honeybee castes. 


\section{CONCLUDING REMARKS}

The saga of the female honeybee brain begins with differential development that favours queens during the larval stage, likely in response to differential nutritional input. This pattern shifts with the larval-pupal moult. During the first part of the pharate-adult developmental period, workers develop larger brains than queens, possibly in response to differences in hormonal environments between the castes. Our working hypothesis is that the observed differences in ecdysteroid levels, in the absence of $\mathrm{JH}$ during pupal and most of pharate-adult development, are translated into differential gene expression profiles in the brain. These effects lead to differential cell proliferation/death in the brains of the two castes. The hormonal environment would thus constitute the physiological link between the nutritionally based differential neurogenesis in the larval stage and the neurogenic processes taking place during the pupal/pharate-adult stage. Hormones are also likely the causal factors that transform a rapidly growing tissue during the larval stage into one that experiences far more cell death in the subsequent developmental stage. This relatively long-lasting effect of high nutritional availability in the presence of high titres of ecdysteroids (but the absence of $\mathrm{JH}$ ) resembles a physiological process found in other systems. It has been shown that high levels of TOR activity in the absence of growth factors promote cell death by excess nutrients (Panieri et al. 2010). Similarly, nutrient excess may induce apoptosis through the action of high levels of the insulin/insulin receptor pathway (Tachibana et al. 2015). In the honeybee brain, the "survival" factor would be $\mathrm{JH}$, the titres of which remain at basal levels until the final phases of the pharate-adult stage (Rembold 1987; Hartfelder and Engels 1998). Thus, it seems that a high nutritional input during larval development may subsequently result in diminished neurogenesis, likely due to lower cell survival. This hypothesis is currently being tested in our laboratory.

Another pending issue in the saga of brain development is that of the absolute MB size and the brain volume/body volume ratio, which favour newly emerged workers. Does this phenomenon accompany the evolution of sociality in bees?
There are data supporting the notion that size differences between female bees increase along with the level of sociality. Hallmark examples, as presented by Michener (1974), are the increasing trend in mean size variation among unfertilized workers and bees with enlarged ovaries in Augochloropsis sparsilis (Augochlorini, a semisocial species). This state is followed by the size dimorphism found in Lasioglossum malachurum (Halictini, a primitively eusocial species) and in Lasioglossum imitatum, which features an additional sociobiological relevant characteristic. Specifically, female size diphenism in this species is accompanied by a proportional allometry regarding ovary development (activated by oogenesis), including ovariole number (as in L. laevissimum, Packer 1992). Within Allodapini, the Australian bee Exoneura variabilis shows size differentiation between workers and egg-layers, a difference that is also accompanied by differential ovary activation. In addition, there are certain species of the genus Bombus (also primitively eusocial) with remarkable differences in female size as well as in physiology, behaviour, and even coloration. The final stage is represented by highly eusocial bees (e.g. the genus Apis, Apini, and the stingless bees, Meliponini; see Sakagami 1982). As in honeybees, there are differences in caste size that are reflected in brain size differences, and there is a general trend in increasing caste size differences with increasing levels of sociality. Brain development in the highly eusocial honeybee might thus be a paradoxical case that represents a by-product of the evolution of reproductive division of labour in species with female size diphenism. Therefore, A. mellifera castes fit the social brain model, which states that interactions with conspecifics represent cognitive challenges to animals and that any increase in social complexity favours the development of larger brains (Dunbar and Shultz 2007). Thus, it may be that evolutionary caste differences in bees were promoted by developmental morphophysiological trade-offs in which the caste specialising in reproduction invested in ovary development and function, and the non-reproductive multi-task caste invested in brain development (and the other behavioural facilitating structures, such as the corbicula). To test if the evolution of this phenomenon occurred in bees and thus agrees with the social 
brain hypothesis (wasps, for example, seem to follow an opposite pattern, O'Donnell et al. 2015), studies must be performed on the allometric relationships between body regions in bees of different sociality levels, as well as on the conservation of the gene expression networks that mediate honeybee caste brain diphenism.

\section{ACKNOWLEDGEMENTS}

We thank Paulo EF Alvarenga (UNIFAL-MG), Marcela Laure, and Luiz Aguiar (FMRP-USP) for technical assistance in sampling brains, as well as Zilá LP Simões, Marcia Bitondi and Erica Tanaka for helpful discussions. We also thank Zilá LP Simões and Klaus Hartfelder for critically reading a previous version of the MS.

This research was supported by Fundação de Amparo à Pesquisa do Estado de Minas Gerais (FAPEMIG APQ02134-14) and FINEP/PROINFRA 01/2008. ARB is supported by CNPq (Conselho Nacional de Desenvolvimento Científico e Tecnológico, Proc. 307426/2014-9). We also thank Lisete M. Rosa (Sítio das Rosas) and Prof. Antônio M. Siqueira (Fazenda da Lagoa) for generously allowing the installation of our experimental apiary.

\section{AUTHORS' CONTRIBUTION}

ARB conceived this research and designed experiments; LMRM participated in the design and interpretation of the data; GDS, RDC and DEPJ performed experiments and analysis; $A R B$ and LMRM wrote the paper. All authors read and approved the final manuscript.

\section{OPEN ACCESS}

This article is distributed under the terms of the Creative Commons Attribution 4.0 International License (http://creativecommons.org/licenses/by/4.0/), which permits unrestricted use, distribution, and reproduction in any medium, provided you give appropriate credit to the original author(s) and the source, provide a link to the Creative Commons license, and indicate if changes were made.

\section{Ontogénèse d'un cerveau social}

Apis mellifera / abeille / développement / caste / plasticité phénotypique
Die Ontogenese eines sozialen Gehirns

Apis mellifera / Honigbiene / Entwicklung / Kaste / phänotypische Plastizität

\section{REFERENCES}

Altenhein B. (2015) Glial cell progenitors in the Drosophila embryo. Wiley Online Library 63:1291-1302. https://doi.org/10.1002/glia.22820

Antonialli W.F. Jr, Cruz-Landim C. (2006) Effect of topical application of juvenile hormone on the occurrence of cell death in the larvae of honeybee (Apis mellifera). Braz. J. Morphol. Sci. 23:377-383

Asencot M., Lensky Y. (1976) The effect of sugars and juvenile hormone on the differentiation of the female honeybee larvae (Apis mellifera L.) to queens. Life Sci. 18:693700. https://doi.org/10.1016/0024-3205(76)90180-6

Ashby R, Forêt S, Searle I, Maleszka R (2016) MicroRNAs in honey bee caste determination. Sci. Rep. 6, 18794. https://doi.org/10.1038/srep18794

Barchuk A.R., Cristino A.S., Kucharski R., Costa L.F., Simões Z.L.P., et al. (2007) Molecular determinants of caste differentiation in the highly eusocial honeybee Apis mellifera. BMC Dev. Biol. 7:70. https://doi. org/10.1186/1471-213X-7-70

Bomtorin AD, Barchuk AR, Moda LM, Simões ZLP (2012) Hox gene expression leads to differential hind leg development between honeybee castes. PLoS ONE 7(7). https://doi.org/10.1371/journal.pone.0040111

Boone JQ, Doe CQ (2008) Identification of Drosophila type II neuro-blast lineages containing transit amplifying ganglion mother cells. Dev Neurobiol 68:11851195. https://doi.org/10.1002/dneu.20648

Burda H, Honeycutt RL, Begall S, Locker-Grutjen O, Scharff A (2000). Are naked and common mole-rats eusocial and if so, why? Behav Ecol Sociobiol 47:293303. https://doi.org/10.1007/s002650050669

Buttstedt A., Ihling C.H., Pietzsch M.P., Moritz R.F.A. (2016) Royalactin is not a royal making of a queen. Nature 537:E10-E12

Cameron RC, Duncan EJ, Dearden PK (2013) Biased gene expression in early honeybee larval development. BMC Genomics 14:903. https://doi.org/10.1186 /1471-2164-14-903

Campos-Ortega J.A., Hartenstein V. (1997) The embryonic development of Drosophila melanogaster. SpringerVerlag, New York

Capella I.C.S., Hartfelder K. (1998) Juvenile hormone effect on DNA synthesis and apoptosis in castespecific differentiation of the larval honey bee (Apis mellifera L.) ovary. J. Insect Physiol. 44:385-391. https://doi.org/10.1016/S0022-1910(98)00027-4

Cayre M, Strambi C, Charpin P, Augier R, Meyer MR, et al. (1996) Neurogenesis in adult insect mushroom bodies. J Comp Neurol 371: 300-310 
Chittka L, Niven J (2009) Are bigger brains better? Curr Biol 21:995-1008. https://doi.org/10.1016/j. cub.2009.08.023

Cristino AS, Barchuk AR, Freitas FCP Narayanan RK, Biergans SD, et al. (2014) Neuroligin-associated microRNA-932 targets actin and regulates memory in the honeybee. Nat Commun 5:5529. https://doi. org/10.1038/ncomms6529

Cruz-Landim C (2009) Abelhas: morfologia e função de sistemas. Unesp Press, 408p. https://doi.org/10.7476 /9788539304301

Doe CQ (1992) Molecular markers for identified neuroblasts and ganglion mother cells in the Drosophila central nervous system. Development 116: 855-863

Du Praw EJ (1967) The honeybee embryo. Crowell, New York

Dunbar RIM, Shultz S (2007) Evolution in the social brain. Science 317:1344-1347

Emmett DJ, Morrison CL, Rios R (2000). Multiple origins of eusociality among sponge-dwelling shrimps (Synalpheus). Evolution 54:503-516. https://doi. org/10.1111/j.0014-3820.2000.tb00053.x

Erber J (1975) The dynamics of learning in the honey bee (Apis mellifica carnica) II. Principles of information processing. J Comp Physiol 99:243-255

Fahrbach SE, Giray T, Robinson GE (1995a). Volume changes in the mushroom bodies of adult honeybee queens. Neurol learn mem. 63(2):181-91. https://doi. org/10.1006/nlme.1995.1019

Fahrbach SE, Strande JL, Robinson GE (1995b) Neurogenesis is absent in the brains of adult honey bees and does not explain behavioral neuroplasticity. Neurosci Lett 2:145-148. https://doi.org/10.1016 /0304-3940(95)11913-H

Farris SM, Sinakevitch I (2003) Development and evolution of the insect mushroom bodies: towards the understanding of conserved developmental mechanisms in a higher brain center. Arthropod Struct Dev 32:79-101. https://doi. org/10.1016/S1467-8039(03)00009-4

Farris SM, Robinson GE, Davis RL, Fahrbach SE (1999) Larval and pupal development of the mushroom bodies in the honey bee, Apis mellifera . J Comp Neurol 414:97113

Farris SM, Robinson GE, Fahrbach SE (2001) Experienceand age-related outgrowth of intrinsic neurons in the mushroom bodies of the adult worker honeybee. J Neurosci 21:6395-6404

Feinerman O, Traniello JFA (2016) Social complexity, diet, and brain evolution: modeling the effects of colony size, worker size, brain size, and foraging behavior on colony fitness in ants. Behav Ecol Sociobiol 70:1063-1074. https://doi.org/10.1007/s00265-015-2035-5

Fleig R, Sander K (1986) Embryogenesis of the honeybee Apis mellifera L. (Hymenoptera: Apidae): an SEM study. J Insect Morphol Embryol 15:449-462

Foster KR and Ratnieks FLW (2005) A new eusocial vertebrate? Trends Ecol Evol 20:363-364. https://doi. org/10.1016/j.tree.2005.05.005
Ganeshina O, Schafer S, Malun D (2000) Proliferation and programmed cell death of neuronal precursors in the mushroom bodies of the honeybee. J Comp Neurol 417:349-365. https://doi.org/10.1002/(SICI)10969861(20000214)417:3<349::AID-CNE8>3.0.CO;2-E

Gilbert SF and Barresi MJ (2016) Developmental biology. Sunderland: Sinauer Associates

Groh C, Rossler W (2008) Caste-specific postembryonic development of primary and secondary olfactory centers in the female honeybee brain. Arthropod Struct Dev 37:459-468. https://doi.org/10.1016/j. asd.2008.04.001

Groh C, Tautz J, Rossler W (2004) Synaptic organization in the adult honey bee brain is influenced by broodtemperature control during pupal development. Proc Nat Acad Sci USA 101:4268-4273. https://doi. org/10.1073/pnas.0400773101

Guo X, Su S, Skogerboe G, Dai S, Li W, et al. (2013) Recipe for a busy bee: MicroRNAs in honey bee caste determination. PLoS ONE 8(12): e81661. https://doi. org/10.1371/journal.pone.008166

Haberkern H, Jayaraman V (2016) Studying small brains to understand the building blocks of cognition. Curr Opin Neurobiol 37:59-65. https://doi.org/10.1016/j. conb.2016.01.007

Hähnlein I, Bicker G (1997) Glial patterning during postembryonic development of central neuropiles in the brain of the honeybee. Dev Genes Evol 207:2941. https://doi.org/10.1007/s004270050089

Hartenstein V, Wodarz A (2013) Initial neurogenesis in Drosophila. Wiley Interdiscip Rev Dev Biol 2:701721. https://doi.org/10.1002/wdev.111

Hartfelder K, Engels W (1998) Social insect polymorphism: Hormonal regulation of plasticity in development and reproduction in the honeybee. Curr Top Dev Biol 40:45-77. https://doi.org/10.1016/S0070-2153 (08)60364-6

Homem C, Repic M, Knoblich, JA (2015) Proliferation control in neural stem and progenitor cells. Nat. Rev. 16: 647-659. https://doi.org/10.1038/nrn4021

Hoover SE, Keeling CI, Winston ML, Slessor KN (2003) The effect of queen pheromones on worker honey bee ovary development. Naturwissenschaften 90:477. https://doi.org/10.1007/s00114-003-0462-z

Huang J, Bonni A (2016) A decade of the anaphasepromoting complex in the nervous system. Genes Dev. 30:622-638. https://doi.org/10.1101 $/ \operatorname{gad} .274324 .115$

Ito K, Hota Y (1992) Proliferation pattern of postembryonic neuroblasts in the brain of Drosophila melanogaster. Dev. Biol. 149:134-148

Jindra M, Palli SR, Riddiford LM (2013) The juvenile hormone signaling pathway in insect development. Annu. Rev. Entomol. 58:181-204. https://doi. org/10.1146/annurev-ento-120811-153700

Kamakura M (2011) Royalactin induces queen differentiation in honeybees. Nature 12:994-1003. https://doi. org/10.1038/nature10093 
Kamakura M (2016) Replies to: Buttstedt A, Ihling CH, Pietzsch MP, Moritz RFA. Royalactin is not a royal making of a queen. Nature 537:E13

Kapheim KM, Pan H, Li C, Salzberg SL, Puiu D, et al. (2015) Social evolution. Genomic signatures of evolutionary transitions from solitary to group living. Science 348:1139-1143

Kenyon FC (1896) The brain of the bee. J. Comp Neurol. 6:133-210

Knust E, Campos-Ortega JA (1989) The molecular genetics of early neyrogenesis in Drosophila melanogaster. Bioessays 4:95-100. https://doi.org/10.1002 /bies.950110405

Koniszewski NDB, Kollmann M, Bigham M, Farnworth M, $\mathrm{He} \mathrm{B}$, et al. (2016) The insect central complex as model for heterochronic brain development-background, concepts, and tools. Dev. Genes Evol. 3:209-219. https://doi.org/10.1007/s00427-016-0542-7

Kucharski R, Maleszka J, Foret S, Maleszka R (2008) Nutritional control of reproductive status in honeybees via DNA methylation. Science 319:1827. https://doi. org/10.1126/Science.1153069

Kucharski R, Foret S, Maleszka R (2015) EGFR gene methylation is not involved in Royalactin controlled phenotypic polymorphism in honey bees. Sci. Rep. 5:14070. https://doi.org/10.1038/srep14070

Lago DC, Humann FC, Barchuk AR, Abraham KJ, Hartfelder K (2016) Differential gene expression underlying ovarian phenotype determination in honey bee, Apis mellifera L., caste development. Insect Biochem Mol Biol 79:1-12. https://doi.org/10.1016/j. ibmb.2016.10.001

Leimar O, Hartfelder K, Laubichler MD, Page Jr, RE (2012) Development and evolution of caste dimorphism in honeybees - a modeling approach. Ecol. Evol. 2:30983109. https://doi.org/10.1002/ece3.414

Levin M (2012) Morphogenetic fields in embryogenesis, regeneration, and cancer: non-local control of complex patterning. Biosystems 109:243-261. https://doi. org/10.1016/j.biosystems.2012.04.005

Liebl EC, Forsthoefel DJ, Franco LS, Sample SH, Hess JE, et al (2000) Dosage-sensitive, reciprocal genetic interactions between the Abl tyrosine kinase and the putative GEF trio reveal trio's role in axon pathfinding. Neuron 26:107-118. https://doi.org/10.1016/S08966273(00)81142-3

Maestro JL, Cobo J, Bellés X (2009) Target of Rapamycin (TOR) mediates the transduction of nutritional signals into juvenile hormone production. J Biol Chem 284:5506-5513. https://doi.org/10.1074/jbc. M807042200

Malun D (1998) Early development of mushroom bodies in the brain of the honeybee Apis mellifera as revealed by BrdU incorporation and ablation experiments. Learn Mem 1:90-101. https://doi.org/10.1101/1m.5.1.90

Malun D, Moseleit AD, Grünewald B (2003) 20hydroxyecdysone inhibits the mitotic activity of neuronal precursors in the developing mushroom bodies of the honeybee Apis mellifera. J. Neurobiol. 57:1-14. https://doi.org/10.1002/neu.10251

Marco Antônio DS, Hartfelder K (2016) Toward an understanding of divergent compound eye development in drones and workers of the honeybee (Apis mellifera L.): A correlative analysis of morphology and gene expression. J. Exp. Zool. B Mol Dev Evol 00B:1-18. https://doi. org/10.1002/jez.b.22696

Medved V, Huang ZY, Popadic A (2014) Ubx promotes corbicular development in Apis mellifera. Biol. Lett. 10:20131021. https://doi.org/10.1098/rsbl.2013.1021

Menzel R (2012) The honeybee as a model for understanding the basis of cognition. Nat Rev. Neurosci. 11:758768. https://doi.org/10.1038/nrn3357

Menzel R (2014) The insect mushroom body, an experience-dependent recoding device. J. Physiol. Paris 108:84-95. https://doi.org/10.1016/j. jphysparis.2014.07.004

Michelette ERF, Soares AEE (1993) Characterization of preimaginal developmental stages in Africanized honey bee workers (Apis mellifera L). Apidologie 24:431-440

Michener CD (1974) The social behavior of the bees: a comparative study. Harvard University Press, Cambridge

Miklos GLG, Maleszka R (2011) Epigenomic communication systems in humans and honey bees: from molecules to behavior. Horm. Behav. 59:399-406. https://doi.org/10.1016/j.yhbeh.2010.05.016

Mobbs PG (1982) The brain of the honeybee Apis mellifera. I. The connections and spatial organization of the mushroom bodies. Phil. Trans. R. Soc. Lond. B 298:309-354

Moda LM, Vieira J, Freire ANC, Bonatti V, Bomtorin AD, Barchuk AR, et al. (2013) Nutritionally driven differential gene expression leads to heterochronic brain development in honeybee castes. PLos ONE. 8(5): e64815. https://doi.org/10.1371/journal.pone.0064815

Monsma SA, Booker R (1996) Genesis of the adult retina and outer optic lobes of the moth, Manduca sexta. II. Effects of deafferentation and developmental hormone manipulation. J Comp Neurol 367:21-35

Mutti NS, Dolezal AG, Wolschin F, Mutti JS, Gill KS, et al. (2011) IRS and TOR nutrient-signaling pathways act via juvenile hormone to influence honey bee caste fate. J. Exp. Biol. 214:3977-3984. https://doi.org/10.1242 /jeb.061499

Nelson JA (1915) The embriology of the honeybee. Princeton, New York

Nelson JA (1924) Morphology of the honeybee larva. J. Agric. Res. 28:1167-1213

O’Donnell S, Bulova SJ, DeLeon S, Khodak P, Miller S, et al. (2015) Distributed cognition and social brains: reductions in mushroom body investment accompanied the origins of sociality in wasps (Hymenoptera: Vespidae). Proc. R. Soc. B 282:20150791. https://doi. org/10.1098/rspb.2015.0791 
Packer L (1992) The social organisation of Lasioglossum (Dialictus) laevissimum (Smith) in southern Alberta. Can J. Zool 70:1767-1774

Pandey R, Blanco J, Udolph G (2011) The Glucuronyltransferase GlcAT-P is required for stretch growth of peripheral nerves in Drosophila. PLOS ONE 6 (11): e28106. https://doi.org/10.1371/journal. pone.0028106

Panieri E, Toietta G, Mele M, Labate V, Ranieri SC, et al (2010) Nutrient withdrawal rescues growth factordeprived cells from mTOR-dependent damage. Aging 2:487-503.

Pankiw T, Huang Z-Y, Winston ML, Robinson GE (1998) Queen mandibular gland pheromone influences worker honey bee (Apis mellifera L.) foraging ontogeny and juvenile hormone titers. J. Insect Physiol. 44:685-692

Parthasarathy R, Palli SR (2007) Stage- and cell-specific expression of ecdysone receptors and ecdysoneinduced transcription factors during midgut remodeling in the yellow fever mosquito, Aedes aegypti. J. Insect Physiol 53:216-229

Patel A, Fondrk MK, Kaftanoglu O, Emore C, Hunt G, et al (2007) The making of a queen: TOR pathway is a key player in diphenic caste development. PLoS ONE, 2:1-7. https://doi.org/10.1371/journal.pone.0000509

Pinto LZ, Hartfelder K, Bitondi MMG, Simões ZLP (2002) Ecdysteroid titers in pupae of highly social bees relate to distinct modes of caste development. J. Insect Physiol 48:783-790. https://doi.org/10.1016/S0022-1910 (02)00103-8

Pinto LZ, Laure MAFB, Bitondi MMG, Hartfelder K, Simões ZLP (2003) Ventral nerve cord remodeling in a stingless bee (Melipona quadrifasciata anthidioides, Hymenoptera, Apidae) depends on ecdysteroid fluctuation and programmed cell death. Int. J. Dev. Biol. 47:385-388

Rachinsky A, Strambi C, Strambi A, Hartfelder K (1990) Caste and metamorphosis: Hemolymph titers of Juvenile Hormone and Ecdysteroids in last instar honeybee larvae. Gen. Comp. Endocrinol. 79:3138

Rembold H (1987) Caste specific modulation of juvenile hormone titers in Apis mellifera. Insect Biochem. 17:1003-1006

Rembold H, Hanser G (1964) Uber den Weiselfuttersaft der Honigbiene, VIII. Nachweis des determinierenden Prinzips im Futtersaft der Königinnenlarven. Hoppe Syler's Z Physiol Chent 339:251-254

Rembold H, Czoppelt C, Rao PJ (1974) Effect of juvenilehormone treatment on caste differentiation in honeybee, Apis mellifera. J. Insect Physiol 7:1193-1202. https://doi.org/10.1016/0022-1910(74)90225-X

Rembold H, Kremer J-P, Ulrich GM (1980) Characterization of postembryonic developmental stages of the female castes of the honey bee, Apis mellifera L. Apidologie 11:29-38

Ress C, Holtmann M, Maas U, Sofsky J, Dorn A (2000) 20Hydroxyecdysone-induced differentiation and apoptosis in the Drosophila cell line, 1(2)mbn. Tussue Cell 32:464-477
Reuter JE, Nardine TM, Penton A, Billuart P, Scott EK, et al (2003) A mosaic genetic screen for genes necessary for Drosophila mushroom body neuronal morphogenesis. Development 130:1203-13. https://doi. org/10.1242/dev.00319

Riddiford LM, Truman JW, Mirth CK, Shen Y (2010) A role for juvenile hormone in the prepupal development of Drosophila melanogaster. Development 137:1117-1126

Roat TC, Cruz Landim C (2008) Temporal and morphological differences in post-embryonic differentiation of the mushroom bodies in the brain of workers, queens, and drones of Apis mellifera (Hymenoptera, Apidae). Micron 39: 1171-1178. https://doi.org/10.1016/j. micron.2008.05.004

Roat TC, Cruz Landim C (2010a) Differences in mushroom bodies morphogenesis in workers, queens and drones of Apis mellifera: neuroblasts proliferation and death. Micron 41:382-389. https://doi.org/10.1016/j. micron.2010.01.003

Roat TC, Cruz Landim C (2010b) Mitosis and cell death in the optic lobes of workers, queens and drones of the honey bee (Apis mellifera) during metamorphosis. J. Biosci. 35:415-425

Roat TC, Cruz-Landim C (2011) Differentiation of the honey bee (Apis mellifera L.) antennal lobes during metamorphosis: a comparative study among castes and sexes. Anim. Biol. 61:153-161. https://doi. org/10.1163/157075511X566489

Robinson GE (1992) Regulation of division of labor in insect societies. Annu. Rev. Entomol. 37:637-665. https://doi. org/10.1146/annurev.en.37.010192.003225

Sakagami SF (1982) Stingless bees. In: Hermann HR (ed) Social Insects, Academic Press, 3rd. New York, pp. 361-423

Schmidt Capella IC, Hartfelder K (2002) Juvenilehormone-dependent interaction of actin and spectrin is crucial for polymorphic differentiation of the larval honey bee ovary. Cell Tissue Res. 307:265-272. https:/doi.org/10.1007/s00441-001-0490-y

Shi B, Liang J, Yang X, Wang Y, Zhao Y, et al. (2007) Integration of estrogen and Wnt signaling circuits by the polycomb group protein EZH2 in breast cancer cells. Mol. Cell. Biol. 27:5105-5119. https://doi. org/10.1128/MCB.00162-07

Snodgrass RE (1910) The anatomy of the honey bee. Government Printing Office, Washington

Snodgrass RE (1935) Principles of insect morphology. Cornell, Michigan

Strausfeld NJ (2002) Organization of the honey bee mushroom body: representation of the calyx within the vertical and gamma lobes. J. Comp. Neurol. 1:4-33. https://doi.org/10.1002/cne.10285

Strauss R, Heisenberg M (1993) A higher control center of locomotor behavior in the Drosophila brain. J. Neurosci. 5:1852-1861

Tachibana K, Sakurai K, Yokoh H, Ishibashi T, Ishikawa K, et al. (2015) Mutation in insulin receptor attenuates oxidative stress and apoptosis in pancreatic beta-cells 
induced by nutrition excess: reduced insulin signaling and ROS. Horm Metab Res 47:176-183. https://doi. org/10.1055/s-0034-1389990

Tavares DA, Roat TC, Carvalho SM, Silva-Zacarin ECM, Malaspina O (2015) In vitro effects of thiamethoxam on larvae of Africanized honey bee Apis mellifera (Hymenoptera: Apidae). Chemosphere 135:370-378

Tomé HVV, Martins GF, Lima MAP, Campos LAO, Guedes RNC (2012) Imidacloprid-induced impairment of mushroom bodies and behavior of the native stingless bee Melipona quadrifasciata anthidioides. PLoS ONE 7:1-9. https://doi.org/10.1371/journal. pone.0038406

Toth AL, Robinson GE (2007) Evo-devo and the evolution of social behavior. Elsevier Ltd. https://doi. org/10.1016/j.tig.2007.05.001

Ulrich GM, Rembold H (1983) Caste-specific maturation of the endocrine system in the female honey bee larva. Cell Tiss. Res. 230:49-55. https://doi.org/10.1007 /BF00216026

Urbach R, Technau GM (2003) Early steps in building the insect brain: neuroblast formation and segmental patterning in the developing brain of different insect species. Arthropod Struct. Dev. 32:103-123. https://doi.org/10.1016/S1467-8039(03)()()()42-2

Vleurinck C, Raub S, Sturgill D, Oliver B, Beye M (2016) Linking genes and brain development of honeybee workers: A Whole-Transcriptome approach. PLoS ONE 1:1-12. https://doi.org/10.1371/journal. pone. 0157980

Weaver N (1966) Physiology of caste determination. Annu Rev Entomol 11:79-102. https://doi.org/10.1146 /annurev.en.11.010166.000455

Wheeler WM (1891) Neuroblasts in the arthropod embryo. J. Morph 4:337-343

Wilson EO (1971) The insect societies. Harvard University Press, Cambridge

Withers GS, Fahrbach SE, Robinson GE (1993) Selective neuroanatomical plasticity and division of labour in the honeybee. Nature 364:238-240. https://doi. org/10.1038/364238a0

Wu Y, Parthasarathy R, Bai H, Palli SR (2006) Mechanisms of midgut remodeling: Juvenile hormone analog methoprene blocks midgut metamorphosis by modulating ecdysone action. Mech. Dev. 123:530-547. 